\title{
Large twisted ovarian fibroma associated with Meigs' syndrome, abdominal pain and severe anemia treated by laparoscopic surgery
}

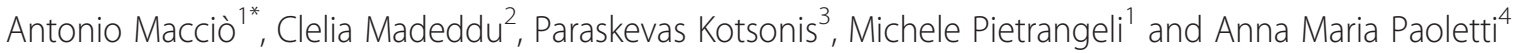

\begin{abstract}
Background: The Meigs' syndrome is a rare but well-known syndrome defined as the triad of benign solid ovarian tumor, ascites, and pleural effusion. Meigs' syndrome always requires surgical treatment. However, the optimal approach for its management has not been sufficiently investigated.

Case presentation: We report a patient with a large twisted ovarian fibroma associated with Meigs' syndrome, abdominal pain and severe hemolytic anemia that was treated by laparoscopic surgery. This case highlights the difficulties that may be encountered in the management of patients with Meigs' syndrome, including potential misdiagnosis of the tumor as a malignant ovarian neoplasm that may influence the medical and surgical approach and the adverse impact that Meigs' syndrome can have on the patient's condition, especially if it is associated with acute pain and severe anemia. Considering the patient's serious clinical condition and assuming that she had Meigs' syndrome with a twisted large ovarian mass and possible hemolytic anemia, we first concentrated on effective medical management of our patient and chose the most appropriate surgical treatment after laparoscopic examination. The main aim of our initial approach was preoperative management of the anemia. Blood transfusions and glucocorticoid therapy resulted in stabilization of the hemoglobin level and normalization of the bilirubin levels, which confirmed the appropriateness of this approach. Laparoscopic surgery 4 days after admission enabled definitive diagnosis of the tumor, confirmed torsion and removed the bulky ovarian fibroma, resulting in timely resolution of symptoms, short hospitalization, relatively low morbidity and a rapid return to her social and professional life.

Conclusions: This case highlights the difficulties that may be encountered in the management of patients with Meigs' syndrome, including potential misdiagnosis of the tumor as a malignant ovarian neoplasm that may influence the medical and surgical approach, and the adverse impact that Meigs' syndrome can have on the patient's condition, especially if it is associated with acute pain and severe anemia. The present case suggests that laparoscopic surgery for potentially large malignant tumors is feasible and safe, but requires an appropriate medical and gynecological oncology expertise.
\end{abstract}

Keywords: Meigs' syndrome, Laparoscopy, Hemolytic anemia, Ovarian fibroma

\section{Background}

Ovarian fibromas belong to the group of sex cord-stromal cell tumors and are the most common benign solid tumors of the ovary, accounting for $1-4 \%$ of all benign ovarian tumors [1,2]. The most frequent symptoms are abdominal discomfort and pain, but many patients do not experience any specific symptoms. These solid tumors are

\footnotetext{
* Correspondence: a.maccio@tin.it

'Department of Gynecologic Oncology, Businco Hospital, Regional Referral

Center for Cancer Disease, via Edward Jenner, Cagliari 09121, Italy

Full list of author information is available at the end of the article
}

often difficult to diagnose based on preoperative ultrasonography findings and are commonly misdiagnosed as uterine myomas. They are also sometimes misdiagnosed as malignant ovarian tumors because of accompanying ascites and an increased serum CA-125 level [3]. Ovarian fibromas account for the majority of benign tumors causing Meigs' syndrome, which is a rare but well-known syndrome defined as the triad of benign solid ovarian tumor, ascites and pleural effusion [4].

Almost all cases of ovarian fibroma can be cured by surgical excision [3]. However, the optimal approach for 
the management of ovarian fibromas has not been sufficiently investigated. Surgeons may be reluctant to remove the tumor laparoscopically as it can be difficult to safely remove the excised tumor from the abdominal cavity. However, recent advancements in operative instruments and techniques have resulted in laparoscopic surgery becoming increasingly popular among gynecological surgeons.

We report a patient with a large twisted ovarian fibroma associated with Meigs' syndrome, abdominal pain and severe anemia that was treated by laparoscopic surgery. This case highlights the difficulties that may be encountered in the management of patients with Meigs' syndrome, including potential misdiagnosis of the tumor as a malignant ovarian neoplasm that may influence the medical and surgical approach and the adverse impact that Meigs' syndrome can have on the patient's condition, especially if it is associated with acute pain and severe anemia.

\section{Case presentation}

A 52-year old woman was referred to the Department of Gynecology at Sirai Hospital, Carbonia, Italy with a 4-hour history of abdominal pain that started in the left lower quadrant and subsequently spread to the whole abdomen. She was pale and in obvious discomfort. Her temperature was $39^{\circ} \mathrm{C}$, blood pressure was $100 / 60 \mathrm{mmHg}$ and heart rate was 120 beats/min. Her past medical history was unremarkable except for intermittent episodes of abdominal discomfort and a sensation of abdominal heaviness during the preceding months.

Physical examination revealed a mass that occupied almost the entire abdomen, extending from the lower abdomen to above the umbilicus and restricting mobility. The uterus and adnexae could not be assessed on bimanual pelvic examination.

Pelvic ultrasonography showed ascites throughout the abdomen and an anteverted, enlarged uterus $(67 \times 54 \times$ $64 \mathrm{~mm}$ ) with a slightly non-homogeneous myometrial echostructure. The maximum endometrium thickness was $16 \mathrm{~mm}$. The adnexal structures were not recognizable. A non-homogeneous mass $(184 \times 121 \times 184 \mathrm{~mm})$ adjacent to the uterus occupied almost the entire abdomen, extending from the hypogastric region to the epigastric region. No flow was detected in the mass on color Doppler or power Doppler ultrasonography. Contrast-enhanced computed tomography showed a large solid left adnexal mass, ascites and bilateral pleural effusions; a thickened and twisted Fallopian tube with a whirlpool sign was also observed, suggesting adnexal torsion. Contrast-enhanced computed tomography did not show enhancement of the adnexal structures, confirming the hypothesis of torsion and necrosis.

The patient's hematological parameters at admission are shown in Table 1. She had severe anemia, total bilirubin level of $4.13 \mathrm{mg} / \mathrm{dl}$, indirect bilirubin level of $3.33 \mathrm{mg} / \mathrm{dl}$, elevated CA-125 level and elevated levels of inflammatory markers including the total white blood cell count, percentage of neutrophils, C-reactive protein (CRP) and fibrinogen.

Considering the patient's serious clinical condition and assuming that she had Meigs' syndrome with a twisted large ovarian mass and possible hemolytic anemia, we implemented intensive medical therapy to prepare her for surgery. She received 5 units of packed red blood cells to correct the anemia. In accordance with the accepted international recommendations for the treatment of hemolytic anemia [5,6], she received intravenous methylprednisolone $500 \mathrm{mg} /$ day (Solu-Medrol ${ }^{\circledR}$; Pfizer, Latina, Italy) for 3 days. She also received subcutaneous low-molecular-weight heparin, antibiotic therapy, albumin infusion and diuretics to avoid progression of her ascites and pleural effusions. Her hematological parameters improved significantly after 3 days, as shown in Table 1. The temporal association between the cessation of hemolysis and glucocorticoid therapy supported our hypothesis of an association between the ovarian tumor and the hemolytic anemia.

After improvement of the patient's condition, we performed laparoscopic surgery on day 4. A port was placed $5 \mathrm{~cm}$ above the umbilicus and a pneumoperitoneum of 10 $14 \mathrm{mmHg}$ was established and maintained throughout the surgery. Intra-abdominal visualization was achieved using a $10 \mathrm{~mm}, 0^{\circ}$ telescope (Karl Storz, Tuttlingen, Germany) and three 5-mm trocars were introduced under laparoscopic visualization through ports in each lower quadrant and in the suprapubic region. A large amount of ascites was aspirated and a large solid mass was observed. The mass was covered by omentum (Figure 1) and adherent to parts of the bowel wall (Figure 2). The liver, gallbladder, stomach and diaphragm were normal in appearance. The mass was carefully freed from the surrounding adherent structures and was found to arise from the twisted left adnexa (Figures 3 and 4). Malignancy was excluded by intraoperative histological examination without the use laparoscopic power morcellator.

The utero-ovarian ligament, Fallopian tube and infundibulopelvic ligament, which were twisted together, were coagulated using BiClamp LAP forceps (ERBE $\mathrm{GmbH}$, Tubingen, Germany) and the ovarian fibroma was resected using monopolar forceps. In accordance with the recent FDA recommendation regarding the use of internal laparoscopic power morcellation for removal of uterus or uterine fibroids [7], the ovarian fibroma was removed from the abdominal cavity with external morcellation through the supraumbilical port, which was enlarged to approximately $6 \mathrm{~cm}$, with the placement of the "Endopath Dextrus", to avoid tumor spillage.

The operating time was about $120 \mathrm{~min}$. There was no significant blood loss and no anesthesia-related complications were observed (Table 1). Postoperative pathologic 
Table 1 Patient's hematological parameters

\begin{tabular}{|c|c|c|c|c|c|}
\hline Parameters & At hospital admittance & Before surgery & 24 hours after surgery & 48 hours after surgery & Hospital discharge \\
\hline Leucocytes $\left(10^{3} / \mu \mathrm{l}\right)$ & 19.6 & 11.0 & 8.5 & 7.0 & 8.6 \\
\hline Neutrophils (\%) & 88.8 & 81.9 & 81.9 & 79.4 & 76.5 \\
\hline Lymphocytes (\%) & 3.8 & 8.7 & 11.5 & 14.3 & 15.7 \\
\hline Red blood cells $\left(10^{6} / \mu \mathrm{l}\right)$ & 1.99 & 4.39 & 4.30 & 4.08 & 4.63 \\
\hline Hematocrit (\%) & 11.3 & 31.2 & 29.9 & 28.5 & 33.3 \\
\hline Hemoglobin (g/dl) & 3.2 & 10.2 & 10.3 & 10.8 & 10.6 \\
\hline Platelets $\left(10^{3} / \mu \mathrm{l}\right)$ & 177 & 136 & 222 & 156 & 222 \\
\hline Ca-125 (U/ml) & 358 & n.v. & n.v. & n.v. & 58 \\
\hline C-reactive protein $(\mathrm{mg} / \mathrm{dl})$ & 20.2 & 11.3 & 5.1 & 2.6 & 0.4 \\
\hline Fibrinogen (mg/dl) & 493 & 364 & 330 & 398 & 393 \\
\hline D-dimer (ng/ml) & 6977 & 250 & 177 & 175 & 170 \\
\hline Total bilirubin (mg/dl) & 4.13 & 1.31 & 0.79 & 1.12 & 0.93 \\
\hline Direct billirubin & 0.77 & 0.58 & 0.45 & 0.50 & 0.37 \\
\hline Indirect bilirubin & 3.33 & 0.73 & 0.34 & 0.62 & 0.56 \\
\hline Total proteins (g/dl) & 4.6 & 6.4 & 6.4 & 6.3 & 6 \\
\hline Albumin (g/dl) & 2.2 & 3.3 & 3.2 & 3.5 & 3.6 \\
\hline
\end{tabular}

Abbreviations: n.v. not evaluable.

examination of the surgical specimen showed complete hemorrhagic necrosis of an ovarian fibroma with evidence of stromal edema (weight 1,930 g) and a 10-cm long necrotic Fallopian tube. Peritoneal cytology showed inflammation but no malignant cells.

The patient was discharged 5 days after surgery (Table 1 ) with a small pleural effusion which resolved approximately 2 weeks after discharge. Seven days after discharge she reported a satisfactory return to her normal social and working activities. One month later she had recovered well and was asymptomatic.

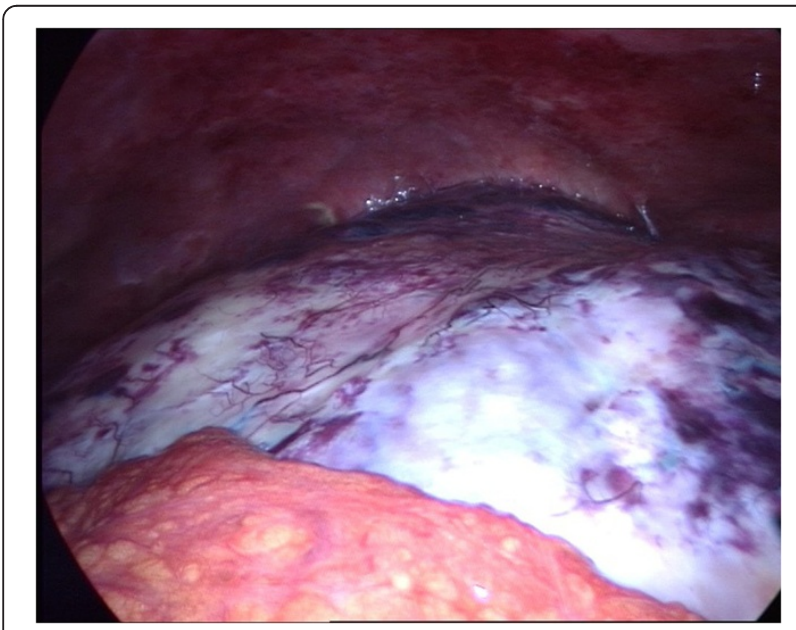

Figure 1 The mass covered by omentum.

\section{Conclusions}

This report presents a rare case of a large twisted ovarian fibroma associated with pain, Meigs' syndrome and severe hemolytic anemia. This case highlights the complexities associated with the diagnosis and treatment of patients with severe complications of benign ovarian disease. In rare cases, ovarian fibromas are associated with ascites and pleural effusions, which is known as Meigs' syndrome [4]. This syndrome is usually associated with large fibromas and high CA-125 levels [8,9]. In the present case, making an accurate diagnosis was complicated by a high CA-125

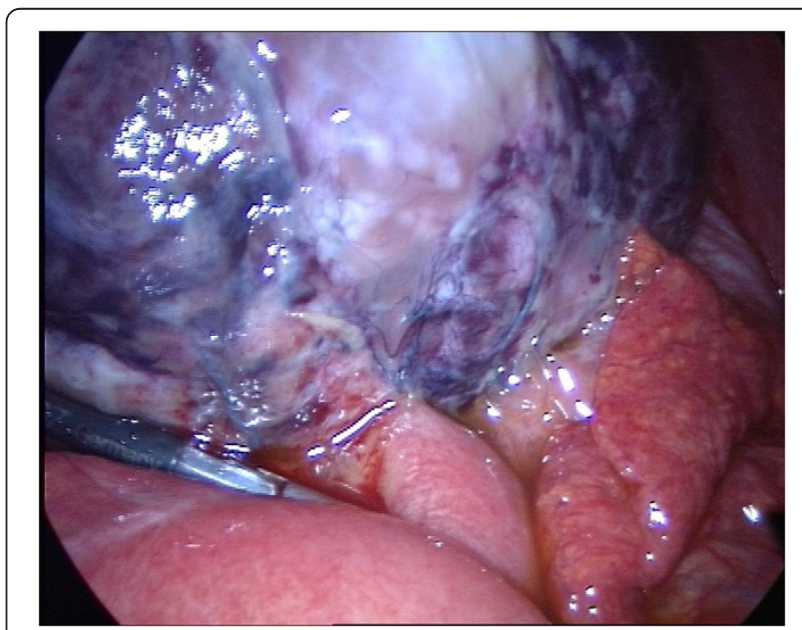

Figure 2 The mass was adherent to parts of the bowel wall. 


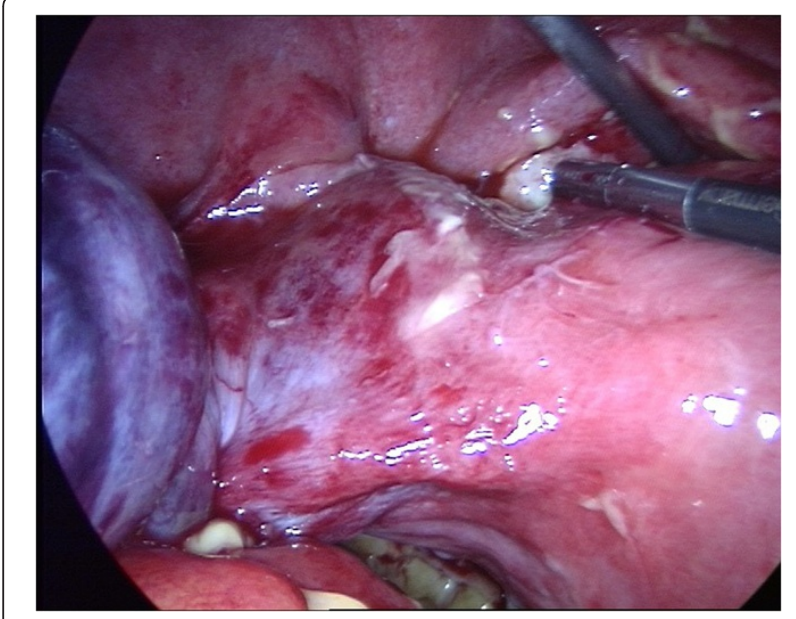

Figure 3 The mass was found to arise from the twisted left adnexa.

level associated with anemia and high levels of inflammatory markers (CRP and fibrinogen). These associations may indicate advanced ovarian cancer [10] and our patient could potentially have been misdiagnosed with a malignant ovarian tumor. However, a high CA-125 level does not necessarily indicate ovarian cancer [11] and can also be associated with ovarian fibroma and the accompanying ascites [12,13]. In addition, torsion of an ovarian fibroma with subsequent necrosis and inflammation can result in increased serum levels of CA-125 and inflammatory markers [14,15]. The serum CA-125 level does not seem to have high specificity for ovarian malignancy unless it is associated with specific ultrasound findings suggesting malignancy [16]. Our patient did not have ultrasound findings suggesting malignancy and her condition was complicated by severe anemia. Anemia is associated with ovarian malignancy, which is also commonly associated

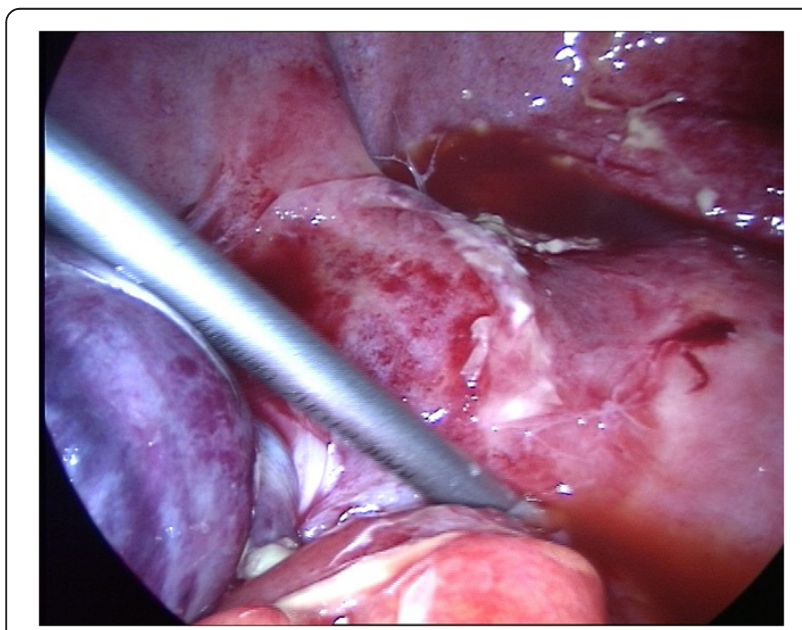

Figure 4 Detail of the twisted adnexa. with high levels of fibrinogen and CRP [10]. In our patient, the serum bilirubin levels suggested hemolytic anemia and the hypoechogenic and acellular echographic characteristics of the effusions excluded ongoing hemorrhage. The association between hemolytic anemia and benign ovarian tumors has been recognized for a long time [17] and complete resolution of the hemolysis has been reported after removal of the tumor [18]. Payne et al. [19] reviewed the clinical courses and responses to ovarian cystectomy in 19 patients with hemolytic anemia and benign ovarian tumors reported in the literature up to 1981. Further 11 cases have been reported since then [20-30], bringing the total to 30 cases. The cases reported in the literature reveal the complexity of managing hemolytic anemia associated with ovarian tumors. One of the previously reported patients showed a good response to glucocorticoid therapy and recovered after ovarian cystectomy within 3 weeks of diagnosis [19]. Two patients died prior to surgery, one because of intestinal obstruction and the other because of a transfusion reaction. One patient underwent simultaneous ovarian cystectomy and splenectomy, resulting in complete recovery. Some patients who did not respond well to initial glucocorticoid therapy or splenectomy recovered well after ovarian cystectomy. These different responses to therapy are interesting, but in our opinion it is difficult to understand why the therapeutic options are considered to conflict with one another, especially when the size of the ovarian tumor and the related symptoms indicate that surgical excision is the treatment of choice, as in our patient. Considering the high impact of splenectomy, it may be useful to initially plan glucocorticoid therapy and surgical excision of the ovarian tumor and perform splenectomy only in patients who do not respond to the initial therapy. We therefore first concentrated on effective medical management of our patient and chose the most appropriate surgical treatment after laparoscopic examination. The main aim of our initial approach was preoperative management of the anemia. Blood transfusions and glucocorticoid therapy resulted in stabilization of the hemoglobin level and normalization of the bilirubin levels, which confirmed the appropriateness of this approach. Laparoscopic surgery was performed after stabilization of the anemia.

We consider that a long waiting time before surgery should be avoided, as cure depends on surgical excision of the tumor, and the pathogenic mechanisms that trigger autoimmune responses in patients with benign ovarian tumors are unknown. It seems appropriate to administer medical therapy, including transfusion, to ensure that patients can undergo early surgery. In our patient, this approach was necessary because of the size of the ovarian mass, the ovarian torsion and the resulting severe pain. Furthermore, it is known that large ovarian masses in Meigs' syndrome are often associated with intra-abdominal hypertension up to abdominal compartment syndrome. The 
chronic development of abdominal hypertension and onset of the abdominal compartment syndrome associated with Meigs' syndrome must be recognized in a timely manner and promptly treated by performing as complete a resection of the pelvic mass as possible [31].

Laparoscopic surgery 4 days after admission enabled definitive diagnosis of the tumor, confirmed torsion and removed the bulky ovarian fibroma, resulting in timely resolution of symptoms, short hospitalization, relatively low morbidity and a rapid return to her social and professional life. Meigs' syndrome always requires surgical treatment and the laparoscopic approach was successful in this case, with careful handling of the tumor because $1 \%$ of well-circumscribed ovarian tumors are malignant $[32,33]$. In cases of large potentially malignant ovarian masses, laparoscopic surgery may have several potential limitations (tumor rupture, spillage, incomplete resection of lesion and trocar insertion site metastasis). On the other hand, a recent review [34] concluded that there was no goodquality evidence to help quantify the risks and benefits of laparoscopy for the management of early-stage ovarian cancer as routine clinical practice.

In conclusion, laparoscopic surgery for potentially malignant tumors may be feasible and safe [35] but requires an experienced gynecological oncology team and is beyond the expertise of the general surgeon [36]. Then, diagnostic laparoscopy is useful in patients with potentially malignant tumors and laparoscopic tumor resection can be performed also if there are signs of malignancy and removal can be achieved without peritoneal contamination. In the present case, laparoscopic resection was feasible, safe and effective for removal of the large ovarian fibroma.

\section{Consent}

Written informed consent was obtained from the patient for publication of this Case Report and any accompanying images.

\section{Abbreviations \\ CRP: C-reactive protein.}

\section{Competing interests}

The authors declare that they have no competing interests.

\section{Authors' contributions}

AM conceived of the study, participated in its design, enrolled the patients and performed the surgical procedures, and drafted the manuscript. CM participated in the study design and coordination and contributed to draft the manuscript. PK participated in the patient assessment, enrolment and surgical treatment. MP participated in the design of the study and coordination. AMP participated in the study design and coordination and helped to draft the manuscript. All authors read and approved the final manuscript.

\section{Acknowledgments}

Work supported by the "Associazione sarda per la ricerca in oncologia ginecologica ONLUS" with a funding from "Fondazione Banco di Sardegna" (project no. 5335, 2014). The authors thank Ivan Collu, Concetta De Simone and Carla Colombini for their technical assistance.

\section{Author details}

'Department of Gynecologic Oncology, Businco Hospital, Regional Referral Center for Cancer Disease, via Edward Jenner, Cagliari 09121, Italy.

2Department of Medical Science "Mario Aresu", University of Cagliari, Cagliari, Italy. ${ }^{3}$ Department of Obstetrics and Gynecology, Sirai Hospital, Carbonia, Italy. ${ }^{4}$ Department of Obstetrics and Gynecology, University of Cagliari, Cagliari, Italy.

Received: 1 October 2013 Accepted: 11 June 2014

Published: 24 June 2014

\section{References}

1. Leung SW, Yuen PM: Ovarian fibroma: a review on the clinical characteristics, diagnostic difficulties, and management options of 23 cases. Gynecol Obstet Invest 2006, 62:1-6.

2. Chechia A, Attia L, Temime RB, Makhlouf T, Koubaa A: Incidence, clinical analysis, and management of ovarian fibromas and fibrothecomas. Am J Obstet Gynecol 2008, 199:473. e1-4.

3. Son CE, Choi JS, Lee JH, Jeon SW, Hong JH, Bae JW: Laparoscopic surgical management and clinical characteristics of ovarian fibromas. JSLS 2011, 15:16-20.

4. Meigs JV, Cass JW: Fibroma of the ovary with ascites and hydrothorax with report of seven cases. Am J Obstet Gynecol 1937, 33:249-266.

5. Lechner K, Jäger U: How I treat autoimmune hemolytic anemias in adults. Blood 2010, 116:1831-1838.

6. Morris PG, Swords R, Sukor S, Fortune A, O'Donnell DM, Conneally E: Autoimmune hemolytic anemia associated with ovarian cancer. J Clin Oncol 2008, 26:4993-4995.

7. Laparoscopic Uterine Power Morcellation in Hysterectomy and Myomectomy: FDA Safety Communication. http://uww.fda.gov/medicaldevices/safety/ alertsandnotices/ucm393576.htm.

8. Moran-mendoza A, Alvarado-luna G, Calderillo-ruiz G, Serrano-Olvera A, Lopez-Graniel CM, Gallardo-Rincon D: Elevated CA125 level associated with Meigs' syndrome: case report and review of the literature. Int $J$ Gynecol Cancer 2006, 16:315-318.

9. Abad A, Cazorla E, Ruiz F, Aznar I, Asins E, Llixiona J: Meigs' syndrome with elevated CA125: case report and review of the literature. Eur J Obstet Gynecol Reprod Biol 1999, 82:97-99.

10. Macciò A, Madeddu C, Massa D, Mudu MC, Lusso MR, Gramignano G, Serpe R, Melis GB, Mantovani G: Hemoglobin levels correlate with interleukin-6 levels in patients with advanced untreated epithelial ovarian cancer: role of inflammation in cancer-related anemia. Blood 2005, 106:362-367.

11. Buamah PK, Skillen AW: Serum CA 125 concentrations in patients with benign ovarian tumours. J Surg Oncol 1994, 56:71-74.

12. Takemori M, Nishimura R, Hasegawa K: Ovarian thecoma with ascites and high serum levels of CA125. Arch Gynecol Obstet 2000, 264:42-44.

13. Sevinc A, Camci C, Turk HM, Buyukberber S: How to interpret serum CA 125 levels in patients with serosal involvement? A clinical dilemma. Oncology 2003, 65:1-6

14. Ghaemmaghami F, Karimi Zarchi M, Hamedi B: High levels of CA125 [over $1,000 \mathrm{lU} / \mathrm{ml}]$ in patients with gynaecologic disease and no malignant conditions: three cases and literature review. Arch Gynecol Obstet 2007 276:559-561.

15. Daponte A, Pournaras S, Hadjichristodoulou C, Lialios G, Kallitsaris A, Maniatis AN, Messinis IE: Novel serum inflammatory markers in patients with adnexal mass who had surgery for ovarian torsion. Fertil Steril 2006, 85:1469-1472.

16. Van Calster B, Timmerman D, Bourne T, Testa AC, Van Holsbeke C, Domali E, Jurkovic D, Neven P, Van Huffel S, Valentin L: Discrimination between benign and malignant adnexal masses by specialist ultrasound examination versus serum CA-125. J Natl Cancer Inst 2007, 99:1706-1714.

17. West-Watson WN, Young CJ: Failed splenectomy in acholuric jaudice and the relation of toxaemia to the hemolytic crisis. Br Med J 1938, 1:1305-1309.

18. Barry KG, Crosby WH: Auto-immune hemolytic anemia arrested by removal of an ovarian teratoma: review of the literature and report of a case. Ann Intern Med 1957, 47:1002-1007.

19. Payne D, Muss HB, Homesley HD, Jobson WW, Baird FG: Autoimmune hemolytic anemia and ovarian dermoid cysts: case report and review of the literature. Cancer 1981, 48:721-724. 
20. Murad MD, Mohler DN, Carpenter JT Jr: Remission of immune hemolytic anemia after removal of ovarian dermoid cyst: case report. Va Med 1982, 109:187-190.

21. Carreras Vescio LA, Toblli JE, Rey JA, Assaf ME, De María HE, Marletta J: Autoimmune hemolytic anemia associated with an ovarian neoplasm. Medicina (B Aires) 1983, 43:415-424.

22. Wassenaar $\mathrm{H}$, van der Meulen FW, Engelfriet CP, Kurstjens RM: Autoimmune hemolytic anemia caused by a dermoid cyst of the ovary. Ned Tijdschr Geneeskd 1984, 128:113-117.

23. Ikeda K, Imazono Y, Shimamoto Y, Sato H, Kaneko S, Nishimura J, Motomura S, Ibayashi H: A case of autoimmune hemolytic anemia associated with ovarian dermoid cyst. Rinsho Ketsueki 1985, 26:212-216.

24. Suzuki H, Sugiki Y, Tanaka T, Hiroshi Y, Suzuki K, Otsu F, Nagasawa G, Isozaki T, Sasaki S: A case of autoimmune hemolytic anemia following ovarian dermoid cyst. Nihon Naika Gakkai Zasshi 1993, 82:1266-1268.

25. Cobo F, Pereira A, Nomdedeu B, Gallart T, Ordi J, Torne A, Monserrat E, Rozman C: Ovarian dermoid cyst-associated autoimmune hemolytic anemia: a case report with emphasis on pathogenic mechanisms. Am J Clin Pathol 1996, 105:567-571.

26. Glorieux I, Chabbert V, Rubie H, Baunin C, Gaspard MH, Guitard J, Duga I, Suc A, Puget C, Robert A: Autoimmune hemolytic anemia associated with a mature ovarian teratoma. Arch Pediatr 1998, 5:41-44.

27. Buchwalter $C L$, Miller $D$, Jenison $E L$ : Hemolytic anemia and benign pelvic tumors. A case report. J Reprod Med 2001, 46:401-404.

28. Agarwal V, Sachdev A, Singh R, Lehl S, Basu S: Autoimmune hemolytic anemia associated with benign ovarian cyst: a case report and review of literature. Indian J Med Sci 2003, 57:504-506.

29. Kim I, Lee JY, Kwon JH, Jung JY, Song HH, Park YI, Ro E, Choi KC: A case of autoimmune hemolytic anemia associated with an ovarian teratoma. J Korean Med Sci 2006, 21:365-367.

30. Raimundo PO, Coelho S, Cabeleira A, Dias L, Gonçalves M, Almeida J: Warm antibody autoimmune haemolytic anaemia associated with ovarian teratoma. BMJ Case Rep 2010, 2010:bcr0620091971.

31. Peparini N, Di Matteo FM, Silvestri A, Caronna R, Chirletti P: Abdominal hypertension in Meigs' syndrome. Eur J Surg Oncol 2008, 34:938-942.

32. Eltabbakh GH: Laparoscopic management of ovarian cysts: before choosing the appropriate surgical procedure, a two pronged approachtransvaginal ultrasonography and CA-125 assesment is the best way to determine the benign or malignant nature of an ovarian mass. Ob Gyn 2003, 48:37-38.

33. Balci O, Icen MS, Mahmoud AS, Capar M, Colakoglu MC: Management and outcomes of adnexal torsion: a 5-year experience. Arch Gynecol Obstet 2011, 284:643-646.

34. Lawrie TA, Medeiros LR, Rosa DD, da Rosa MI, Edelweiss MI, Stein AT, Zelmanowicz A, Ethur AB, Zanini RR: Laparoscopy versus laparotomy for FIGO stage I ovarian cancer. Cochrane Database Syst Rev 2013, 2, CD005344.

35. Querleu D, Leblanc E, Ferron G, Narducci F: Laparoscopic surgery in gynecological oncology. Eur J Surg Oncol 2006, 32:853-858.

36. Târcoveanu E, Dimofte G, Niculescu D, Vasilescu A, Moldovanu R, Ferariu D, Marcovici I: Ovarian fibroma in the era of laparoscopic surgery: a general surgeon's experience. Acta Chir Belg 2007, 107:664-669.

\section{Submit your next manuscript to BioMed Central and take full advantage of:}

- Convenient online submission

- Thorough peer review

- No space constraints or color figure charges

- Immediate publication on acceptance

- Inclusion in PubMed, CAS, Scopus and Google Scholar

- Research which is freely available for redistribution

Submit your manuscript at www.biomedcentral.com/submit
C Biomed Central 